\title{
Application of the Technological, Pedagogical, and Content Knowledge Framework in a Positivist Study on the Use of ICT in Pedagogy by Teachers of Mathematical Disciplines at Makerere University: A Conceptual Paper
}

\author{
Marjorie S. K. Batiibwe ${ }^{1,}{ }^{*}$, Fred E. K. Bakkabulindi ${ }^{1}$, John M Mango ${ }^{1}$ \\ ${ }^{1}$ Makerere University [*Corresponding author: smbatiibwe@cees.mak.ac.ug]
}

\begin{abstract}
ICT provides an array of powerful tools that induce transformation from a teacher-centred to a student-focused and interactive knowledge environment. The use of ICT in pedagogy opens up opportunities for learning because it enables learners to access, extend, transform and share ideas and information in multi-modal communication styles and formats. Therefore, all efforts to enhance it should be expended. One way of enhancing the use of ICT in pedagogy is to isolate the factors that underpin it. It is with this understanding that, basing on the Technological, Pedagogical, and Content Knowledge (TPACK) framework, this paper proposes a positivist study to examine the extent to which knowledge relates with the use of ICT in pedagogy among teachers of mathematical disciplines at Makerere University.
\end{abstract}

Keywords: Mathematical disciplines; Positivism; TPACK.

\section{Background}

\subsection{Historical Perspective}

Majumdar (2006) asserts that ICTs like computers, web 2.0 technologies, Internet, email, and video conferencing provide an array of powerful tools that have induced the transformation of isolated teacher-centred and text-bound classrooms into rich student focused interactive knowledge environments. Majumdar expounds that the use of ICT in pedagogy opens up opportunities for learning because it enables learners to access, extend, transform and share ideas and information in multi-modal communication styles and format. 
ICT helps the learner to share learning resources and spaces, promote learner centred and collaborative learning principles and enhance critical thinking, creative thinking and problem solving skills. Inevitably, all this requires teachers to be more ICT savvy so that they are able to effectively and meaningfully use ICT in pedagogy. Summing up, we can safely say that the use of ICT in pedagogy has a positive impact on the teaching and learning process.

Accordingly, several scholars have devoted their time and effort to the study of use of ICT in pedagogy. While some studies (e.g. Jung, 2005; Nicholson \& Sanber, 2007; Steketee, 2005) dealt with approaches that can be employed when integrating ICT in pedagogy and the pertinent challenges, other studies (e.g. Gill \& Dalgarno, 2010; Gill, Dalgarno \& Carlson, 2015; Mishra \& Koehler, 2006; Taylor, 2004) looked at how teachers developed their understanding of the use of ICT in pedagogy.

Several studies (e.g. Alharbi \& Drew, 2014; Bennison \& Goos, 2010; Fathema, Shannon \& Ross, 2015; Khechine, Lakhal, Pascot \& Bytha, 2014; Pierce \& Ball, 2009; Smarkola, 2007) sought to establish determinants of the use of ICT in pedagogy. However, as suggested by the above studies, there has been a bias towards the developed world, such as the USA (e.g. Bennison \& Goos, 2010; Fathema et al., 2015; Pierce \& Ball, 2009); Canada (e.g. Khechine et al., 2014); and Australia (e.g. Alharbi \& Drew, 2014; Gill \& Dalgarno, 2010; Gill et al., 2015). This contextual gap calls for further research on the use of ICT in pedagogy in the developing world. It is therefore upon such insights that this study proposes to examine the extent to which teachers' knowledge relates with the use of ICT in pedagogy using the teachers of mathematical disciplines in Makerere University.

\section{$1.2 \quad$ Theoretical Perspective}

The purpose of this study is to relate the use of ICT in pedagogy to knowledge and is underpinned by the Technological, Pedagogical, and Content Knowledge (TPACK) framework. The TPACK framework proposed by Mishra and Koehler (2006), postulates that, in order to integrate technology into their teaching, teachers need knowledge, which falls in three major domains, namely content knowledge (CK), pedagogical knowledge (PK) and technological knowledge (TK). Mishra and Koehler defined CK as the "knowledge about the actual subject matter that is to be taught" (p. 1026) and PK as the "knowledge about the processes and practices or methods of teaching and learning and how it encompasses... overall educational purposes, values, and aims" (p. 1026).

They defined TK as the teacher's "knowledge about standard technologies, such as books, chalk and blackboard, and more advanced technologies, such as the Internet and digital video" (p. 1027). The interaction between the three primary knowledge domains, CK, PK and TK gives rise to three secondary 
knowledge domains namely pedagogical content knowledge (PCK), technological content knowledge (TCK) and technological pedagogical knowledge (TPK). These combinations of knowledge, according to TPACK, enhance the use of ICT in pedagogy by teachers. Mishra and Koehler defined PCK as the "knowledge of pedagogy that is applicable to the teaching of specific content" (p. 1027).

Mishra and Koehler defined TCK as the "knowledge about the manner in which technology and content are reciprocally related" (p. 1028); and TPK as the "knowledge of the existence, components, and capabilities of various technologies as they are used in teaching and learning settings, and conversely, knowing how teaching might change as the result of using particular technologies" (p. 1028). When PCK, TCK and TPK knowledge domains interact, they form a triad, technological pedagogical content knowledge (TPACK), which, according to TPACK, is the ideal combination of knowledge needed by a teacher in order to use ICT in pedagogy. The seminal article (Mishra \& Koehler, 2006) defined TPACK as "an emergent form of knowledge that goes beyond all the three components (content, pedagogy, and technology)" (p. 1028).

In summary, TPACK suggests seven knowledge domains namely; CK, PK, TK, PCK, TPK, TCK, TPACK as major determinants of the use of ICT in pedagogy by teachers. These abbreviations feature so much in the remaining part of the paper that the reader is implored to refer to this section when in need of a reminder on what particular abbreviation stands for. TPACK is adopted for this study because in the first position, researchers like Abbitt (2011) contended that "the degree to which [the] perceived TPACK contributes to the demonstrated ability of a... teacher to effectively plan for instructional uses of technology is largely unclear" (p. 297).

Secondly, many past studies in regard to determining user acceptance and the intention to use ICT in pedagogy have focused on other frameworks or models. Such popular frameworks include the Technology Acceptance Model (TAM) of Davis (1989) (e.g. see Alharbi \& Drew, 2014; Fathema et al., 2015) and Innovation Diffusion Theory (IDT) of Rogers (2003) (e.g. see Bakkabulindi, 2012). The Unified Theory of Acceptance and Use of Technology (UTAUT) of Venkatesh, Morris, Davis and Davis (2003) has also been used (e.g. see Khechine et al., 2014) to explain the factors that determine the use of ICT in different disciplines, including pedagogy. Since teaching is a process that calls for specialized knowledge, the study proposed in this conceptual paper will base on the TPACK framework to examine the extent to which knowledge relates with the use of ICT in pedagogy by teachers of mathematical disciplines at Makerere University. 


\subsection{Conceptual Perspective}

On the basis of the TPACK framework (reviewed in subsection 1.2), Figure 1 provides a framework relating the seven knowledge domains of TPACK to the use of ICT in pedagogy (UIP). The dependent variable, has been conceptualized as the use of substitution (S), augmentation (A), modification (M) and redefinition ( $\mathrm{R}$ ) ICTs, that is, using the SAMR model of using ICT (Puentedura, 2010, cited in Lubega, Mugisha, \& Muyinda, 2014). On the other hand, knowledge domains are conceptualized as CK, PK, TK; PCK, TPK, TCK; and TPACK (Mishra \& Koehler, 2006).

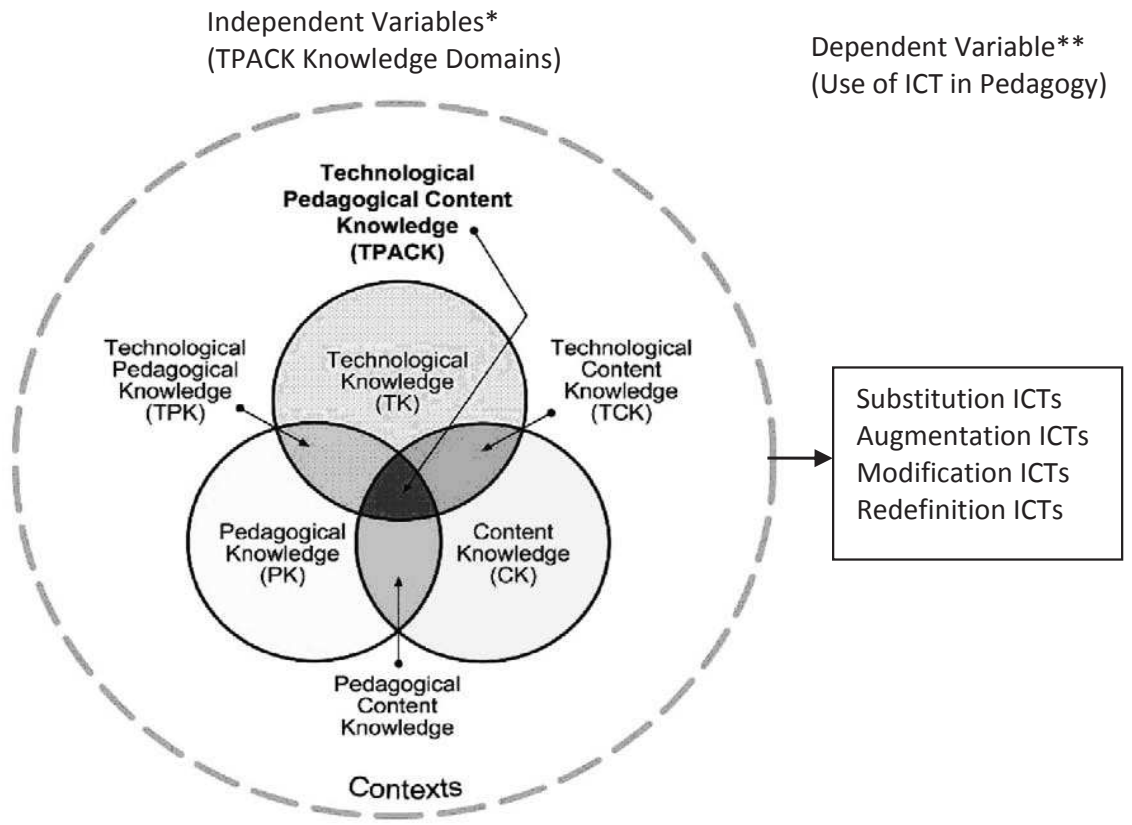

Figure 1: Conceptual framework relating the seven knowledge domains of TPACK and the use of ICT in pedagogy

Source: Adapted from *Mishra and Koehler (2006) and ** Lubega et al. (2014) and Puentedura, 2010)

\section{$2 \quad$ Research Problem}

Although the advantages of using ICT in pedagogy stand out, the academic staff of Makerere University have not fully utilized its ICT facilities (e.g. see 
Bakkabulindi, 2012; Omaswa, 2014). For example, Bakkabulindi (2012) in a study of how perception related to the use of ICT in Makerere University, found that the use of ICT by academic staff was low. The Task Force on job evaluation, re-organization of the staff structure and funding of Makerere University (Omaswa, 2014) reported finding that, despite e-learning being a powerful tool for strengthening teaching and learning capabilities, the University had not fully utilized its potential.

If such a problem of under-utilization of ICT in pedagogy among academic staff persists, there will be a decline in the University's academic standards. Unveiling the correlates of the use of ICT in pedagogy at Makerere University is thus very urgent. Such correlates can be manipulated to enhance the use of ICT in pedagogy at the University. Basing on the TPACK framework (reviewed in subsection 1.2), it is proposed in this paper that knowledge is an explanatory correlate for the use of ICT in pedagogy among the teachers. The domains of knowledge of interest in the proposed study are, CK, PK, TK; PCK, TPK, TCK; and TPACK.

\section{Objectives and Significance}

The main objective of this study is to examine the extent to which knowledge relates with the use of ICT in pedagogy among teachers of mathematical disciplines at Makerere University. The specific objectives of the study are to establish the relationship between CK, PK, TK; PCK, TPK, TCK; and TPACK, each with the use of ICT in pedagogy.

The study will help the Management of the University in enacting and/ or amending pertinent policies in order to see to it that the application of ICT in pedagogy by the entire academic staff is maximized, hence minimizing on the wastage arising from under-utilization of ICT resources. The study findings will also be used by the principals of colleges, deans of schools and chairpersons of departments of mathematical disciplines to improve on the teachers' awareness of the extent to which knowledge is relevant to the use of ICT in pedagogy. Finally, the study findings will augment the knowledge body by contributing to the literature on how knowledge relates to the use of ICT in pedagogy.

\section{$4 \quad$ Related Literature}

Since the inception of the TPACK framework in 2006, several researchers have invested time and effort to employ the framework to guide their studies. Particularly, some researches have made seminal contributions to TPACK, 
while others assessed teachers and/ or students on how much TPACK they possessed. Others dealt with the development of TPACK among teachers and/ or students. Yet others developed and tested survey instruments to measure TPACK, beside those that reviewed literature on TPACK.

\subsection{Seminal Papers on TPACK}

Papers (e.g. Mishra \& Koehler, 2006; Shulman, 1986) that have made original contributions to the development of the TPACK framework are available. As pointed out earlier (subsection 1.3), the TPACK framework (Mishra \& Kohler, 2006) suggests that a teacher's use of ICT in pedagogy, is contingent upon the teacher's knowledge, which knowledge has major domains, namely CK, PK, TK; PCK, TPK, TCK; and TPACK. While the main proponents of TPACK were Mishra and Koehler, their independent variable (IV) was borrowed from Shulman (1986), a seminal article that articulated the importance of knowledge (K) to a teacher. Shulman stressed the importance of CK and PK to the teacher. He gave seminal definitions to the two variables.

In particular, he defined CK as "the amount and organization of knowledge per se in the mind of the teacher" (p. 9). Shulman also gave a seminal definition to PK as the knowledge of how to manage a classroom, organize activities, allocate time and turns, structure assignments, ascribe praise and blame, formulate the levels of their questions, plan lessons, and judge general student understanding. Noting that that CK and PK were inseparable, Shulman proposed another major domain in TPACK, namely "pedagogical content knowledge" (PCK). He gave a seminal definition to it as, "pedagogical knowledge, which goes beyond knowledge of subject matter per se to the dimension of subject matter knowledge for teaching" (p. 9).

Another major contribution of Shulman (1986) to TPACK was to call for the development of the framework. In particular, Shulman noted that:

Although we often present propositions [e.g. on what knowledge a teacher needs in order to use ICT in pedagogy] one at a time, we recognize that they are better understood if they are organized in some coherent form, lodged in a conceptual or theoretical framework.... (pp. $10-11$ ).

With such insights, Mishra and Koehler (2006) came up with the theoretical framework, TPACK, to build on Shulman's PCK by including the knowledge of technology (TK) that teachers require in the teaching and learning process. The details of TPACK are already given in section 1.3.

\subsection{Papers on Assessing TPACK Teachers and/or Students Possess}

Efforts to examine and/ or assess the extent to which teachers and/ or students possess TPACK have been made by several researchers. For example, 
Archambault and Crippen (2009) examined a national sample of 596 K-12 online teachers from 25 different states in the United States and measured their knowledge with respect to the three primary knowledge domains as described by the TPACK framework namely; CK, PK, TK and their combinations. They collected data using a self-created survey instrument whose validity and reliability they had ensured. By using descriptive measures, they found that knowledge ratings were highest among the domains of CK, PK and PCK which implied that these responding online teachers had felt very good about their knowledge related to these domains but were less confident when it came to TK. Using Pearson's product-moment correlation, they found that all the domains and their combinations had high relationships, which finding was "calling into question the distinctiveness of the domains" (Archambault \& Crippen, 2009, p. 71).

\subsection{Papers on the Development of TPACK by Teachers and/ or Students}

There are several papers on the development of TPACK by teachers and/ or students that can be cited. For example, one study (Alayyar, Fisser \& Voogt, 2012) was concerned with developing TPACK in pre-service teachers through working in design teams in the science teacher preparation program at the Public Authority of Applied Education and Training in Kuwait. They separated the participants into two design teams whereby they ensured that one team was only coached by ICT, pedagogy, and content experts while the other was offered a blended condition by which they had access to an online portal with different tutorials and examples as well as the opportunity to meet with different experts whenever they wanted.

They collected pre-test and post-test design data from 78 pre-service teachers through a TPACK survey, attitude to ICT and ICT skill surveys, ICT skill test, team logbook, interview and TPACK reflection questions. Using descriptive statistics and $\mathrm{t}$ tests, they found that the self-reported TPACK, the score of attitudes towards ICT, and ICT skills increased in both groups. They also found that the participants under the blended support condition reported a higher increase in the participants' TK, TPK, their attitude toward ICT as a tool for instruction and productivity, and ICT enjoyment. This suggested that participants perceived the blended condition for supporting design teams as a more desirable method for enhancing their development of TPACK.

\subsection{Papers on the Development and Testing of Instruments to Measure TPACK}

Several researchers have developed and tested instruments to measure TPACK. For example, Chai, Ng, Li, Hong and Koh (2013) attempted to validate a 
TPACK efficacy instrument. They constructed the instrument by adapting parts of earlier instruments. They made adjustments to the adapted items "to reflect the current practices which emphasize the use of ICT for content learning in authentic, intentional, collaboration and active learning environment" (Chai, $\mathrm{Ng}$ et al., 2013, p. 45). They subjected their re-crafted questionnaire containing 36 items to expert review by two professors who had published on TPACK. They then administered the questionnaire which they had translated into Chinese on an Asian group of 550 pre-service teachers from China $(\mathrm{n}=193)$, Hong Kong $(n=52)$, Singapore $(n=210)$ and Taiwan $(n=95)$. Using confirmatory factor analysis, they identified the seven factors underlying the TPACK framework which suggested that the instrument was valid for measuring all the knowledge domains of the pre-service teachers' TPACK.

\subsection{Literature Reviews on TPACK}

Reviews of literature on TPACK have been carried out, including that of the first two authors (Batiibwe \& Bakkabulindi, 2016a, b) of this paper. Among those literature reviews, Chai, Koh and Tsai (2013) reviewed literature on TPACK with the aim of consolidating the collective emerging trends, findings, and issues generated in TPACK research, and to identify gaps. They identified literature by first exploring the Web of Science, Scopus, Education Research Complete and ERIC databases which yielded 74 journal articles. Their review indicated that TPACK was a burgeoning area of research with more applications in the North American region. They brought out the fact that studies that had been conducted had employed varied research methods and they had yielded positive results in enhancing teachers' capability to integrate ICT in pedagogy. However, there were "still many potential gaps that the TPACK framework could be employed to facilitate deeper change in education" (p. 31). In particular, they, among others, called for "crossfertilisation of TPACK with other theoretical frameworks [e.g. Innovation Diffusion Theory, IDT] related to the study of technology integration" (p. 31).

\section{Hypotheses}

Following the literature review (section 4), it becomes apparent that although attention has been given to TPACK in the scholarly world, it has been in other matters than relating TPACK to the use of ICT in pedagogy. Some scholars (e.g. Mishra \& Koehler, 2006; Shulman, 1986) have made original contributions to the development of the TPACK framework. Efforts to assess the extent to which teachers and/ or students possessed TPACK have been made by several researchers (e.g. Archambault \& Crippen, 2009). Other 
researchers (e.g. Alayyar et al., 2012) were concerned with the development of TPACK among teachers and/ or students.

Yet others (e.g. Chai, Ng et al., 2013) developed TPACK instruments, and tested them for validity and reliability. Other efforts (e.g. Chai, Koh \& Tsai, 2013) were towards reviewing literature on TPACK. The cited studies also suggest a bias in favour of the developed world, with the dominance of North America (Chai, Koh \& Tsai, 2013). Studies on the TPACK framework have not yet paid adequate attention to subject matter domains such as Mathematics (Lubke, 2013). Further, the studies on TPACK have dwelt more prominently on pre-service teachers, than in-service teachers (Lubke, 2013), and less so those in Higher Education (Jordan \& Dihn, 2012). The proposed study comes in handy to narrow these gaps by quantitatively examining the relevance of the TPACK framework in explaining the use of ICT in pedagogy (UIP) by teachers of mathematical disciplines in Makerere University. Basing on the conceptual framework (Figure 1), the following hypotheses were generated:

H1: $\quad$ CK positively relates to UIP.

H2: $\quad$ PK positively relates to UIP.

H3: $\quad$ TK positively relates to UIP.

H4: $\quad$ PCK positively relates to UIP.

H5: $\quad$ TPK positively relates to UIP.

H6: $\quad$ TCK positively relates to UIP.

H7: $\quad$ TPACK positively relates to UIP.

\section{$6 \quad$ Methodology}

\subsection{Paradigm and Design}

The proposed study will take the positivist paradigm in that it will be based on variables measured with numbers and analysed with statistical procedures. In particular, the study will be a correlational and cross-sectional survey design. It will be a survey involving a large number of respondents for purposes of generalization. The study will be cross-sectional to the effect that data will be collected from all respondents once and for all to minimize time and costs that could be involved. The study will be correlational because it will involve testing hypotheses to establish the relationship between UIP and the knowledge domains, as suggested by the TPACK framework namely; CK, PK, TK; and their combinations.

\subsection{Data Collection Instrument}

Data will be collected from teachers of mathematical disciplines at Makerere University. A self-administered questionnaire (SAQ) developed basing on 
instruments already used by other scholars (Table 1) will be used to collect the data. The adaptation of the instruments is based on the fact that their reliabilities and validities have been initially taken for granted. With reference to Table 1, the dependent variable (DV), the use of ICT in pedagogy (UIP), has four constructs namely the use of substitution (S), augmentation (A), modification (M), and redefinition (R) ICTs, each of which has a number of items adapted from an earlier instrument. The independent variable (IV), knowledge, has seven constructs as suggested by the TPACK framework each with a number of items adapted from reliable instruments.

\subsection{Data Management}

Whereas the reliabilities of the constructs are already guaranteed by earlier studies as illustrated in Table 1 and their validities implied (Tavakol \& Dennick, 2011), after the collection of data, the reliabilities of the constructs will be retested using Cronbach Alpha method provided by SPSS. Similarly, the validities of multi-item constructs will be tested using Factor Analysis. This retesting will be done because as Tavakol and Dennick observe, differences in samples call for retesting the instruments. To test the hypotheses (section 5) in the study, a regression model of the DV on the seven knowledge domains of the TPACK framework, that is, UIP = $\mathrm{f}(\mathrm{CK}, \mathrm{PK}, \mathrm{TK}, \mathrm{PCK}, \mathrm{TPK}$, TCK, TPACK) will be fitted. SPSS will be used to facilitate the analysis.

Table 1: Variables in the Instrument

\begin{tabular}{|c|c|c|c|}
\hline Variable & Construct & $\begin{array}{l}\text { Items } \\
\text { adapted }\end{array}$ & $\begin{array}{l}\text { Source of instrument, total number of items } \\
\text { therein; and their reliability ( } \alpha \text { value) }\end{array}$ \\
\hline \multirow{4}{*}{$\begin{array}{l}\text { Use of ICT } \\
\text { in pedagogy } \\
\text { (DV) }\end{array}$} & S & 12 & Lubega et al. (2014), 13 items * \\
\hline & A & 9 & Lubega et al. (2014), 16 items * \\
\hline & M & 5 & Lubega et al. (2014), 10 items * \\
\hline & $\mathrm{R}$ & 5 & Lubega et al. (2014), 6 items * \\
\hline \multirow[t]{7}{*}{$\begin{array}{l}\text { Knowledge } \\
\text { (IV) }\end{array}$} & CK & 3 & $\begin{array}{l}\text { Schmidt, Baran, Thompson, Mishra, Koehler } \\
\& \text { Shin (2009), } 3 \text { items }(\alpha=0.85)\end{array}$ \\
\hline & PK & 7 & Schmidt et al. (2009), 7 items $(\alpha=0.84)$ \\
\hline & TK & 7 & Schmidt et al. (2009), 7 items ( $\alpha=0.82)$ \\
\hline & PCK & 5 & Chai, Ng et al. (2013), 5 items $(\alpha=0.92)$ \\
\hline & TPK & 4 & $\begin{array}{l}\text { Chai, Chin, Koh \& Tan (2013), } 4 \text { items } \\
(\alpha=0.90)\end{array}$ \\
\hline & TCK & 4 & Chai, Ng et al. (2013), 5 items $(\alpha=0.92)$ \\
\hline & TPACK & 6 & Chai, Ng et al. (2013), 6 items $(\alpha=0.92)$ \\
\hline
\end{tabular}

* No alpha reported 


\section{$7 \quad$ Conclusion}

The "new" positivist look at how TPACK concepts can be used to explain the use of ICT in pedagogy, as suggested in this paper, is expected to trigger more studies of the same genre. This study and the ones to follow will go a long way in answering Abbitt (2001) who asked, "how much knowledge of technology, pedagogy, content or within blended domains such as TPK, TCK, TPACK... is sufficient for a... teacher" (p. 297) to effectively use ICT in pedagogy?

\section{References}

Abbitt, J. T. (2011). Measuring technological pedagogical content knowledge in pre-service teacher education: A review of current methods and instruments. Journal of Research in Technology in Education, 43(4), 281300.

Alayyar, G. M., Fisser, P., \& Voogt, J. (2012). Developing technological pedagogical content knowledge in pre-service science teachers: Support from blended learning. Australasian Journal of Educational Technology, 28(8), $1298-1316$.

Alharbi, S., \& Drew, S. (2014). Using the technology acceptance model in understanding academics' behavioural intention to use learning management systems. International Journal of Advanced Computer Science and Applications, 5(1), 143-155.

Archambault, L., \& Crippen, K. (2009). Examining TPACK among K-12 online distance educators in the United States. Contemporary Issues in Technology and Teacher Education, 9(1), 71-88. Retrieved from: http://www.citejournal.org/vol9/iss1/general/article2.cfm.

Bakkabulindi, F. E. K. (2012). Does use of ICT relate with the way it is perceived? Evidence from Makerere University. International Journal of Computing and ICT Research, 6(2), 75 - 94. Retrieved from: http://www.ijcir.org/volume6-number2/article7.pdf.

Batiibwe, M, S. K., \& Bakkabulindi, F. E. K. (2016a). Technological Pedagogical Content Knowledge (TPACK) as a theory on factors of the use of ICT in pedagogy: A review of literature. In M. M. Dichaba, \& M. A. O. Sotayo (Eds.), South Africa International Conference on Education, 19 - 21 September 2016 on the theme, "towards excellence in educational practices" (pp. 228 - 241). Pretoria, South Africa: African Academic Research Forum (AARF). http:www.aa-rf.org. ISBN: 978-0-620-72896-6.

Batiibwe, M, S. K., \& Bakkabulindi, F. E. K. (2016b). Technological Pedagogical Content Knowledge (TPACK) as a theory on factors of the use 
of ICT in pedagogy: A review of literature. International Journal of Education and Research, 4(11), 123 - 138. Retrieved from: www.ijern.com.

Bennison, A., \& Goos, M. (2010). Learning to teach mathematics with technology: A survey of professional development needs, experiences and impacts. Mathematics Education Research Journal, 22(1), 31-56. doi: 10.1007/BF03217558

Chai, C. S., Koh, J. H. L., \& Tsai, C-C. (2013). A review of technological pedagogical content knowledge. Educational Technology \& Society, 16(2), $31-51$.

Chai, C. S., Ng, E. M., Li, W., Hong, H. Y., \& Koh, J. H. L. (2013). Validating and modelling technological pedagogical content knowledge framework among Asian pre-service teachers. Australasian Journal of Educational Technology, 29(1), 41-53.

Davis, F. D. (1989). Perceived usefulness, perceived ease of use, and user acceptance of information technology. MIS Quarterly, 13, 319-340.

Fathema, N., Shannon, D., \& Ross, M. (2015). Expanding the Technology Acceptance Model (TAM) to examine faculty use of learning management systems (LMSs) in higher education institutions. Journal of Online Learning \& Teaching, 11(2), 210-232.

Gill, L., \& Dalgarno, B. (2010). How does pre-service teacher preparedness to use ICTs for learning and teaching develop during the first two years of teacher training? In C. H. Steel, M. J. Keppell, P. Gerbic \& S. Housego (Eds.), Curriculum, technology \& transformation for an unknown future: Proceedings of the $27^{\text {th }}$ Australasian Society for Computers in Learning in Tertiary Education Conference (pp. 371-381). Sydney, Australia: ASCILITE.

Gill, L., Dalgarno, B., \& Carlson, L. (2015). How does pre-service teacher preparedness to use ICTs for learning and teaching develop through their degree program? Australian Journal of Teacher Education, 40(1), 36-59.

Jordan, K., \& Dinh, H. (2012). TPACK: Trends in current research. Paper presented at the ACEC2012: Its Time Conference, Perth, Australia. October $2-5$.

Jung, I. (2005). ICT-pedagogy integration in teacher training: Application cases worldwide. Educational Technology and Society, 8(2), 94-101.

Khechine, H., Lakhal, S., Pascot, D., \& Bytha, A. (2014). UTAUT model for blended learning: The role of gender and age in the intention to use webinars. Interdisciplinary Journal of E-Learning and Learning Objects, 10, 33-52.

Lubega, J. T., Mugisha, A. K., \& Muyinda. P. B. (2014). Adoption of the SAMR model to assess ICT pedagogical adoption: A case of Makerere University. International Journal of e- Education, e-Business, eManagement and e-Learning, 4(2), 106-115. 
Lubke, K. J. (2013). An historical review of TPACK: Implications for new literacies researchers and teacher educators. Paper presented at the annual meeting of the Literacy Research Association, Dallas, Texas. December 4-7.

Majumdar, S. (2006). Emerging trends in ICT for education and training. Paper read at the International Conference on Education Technology and Training, Helsinki, Finland. August 24-28.

Mishra, P., \& Koehler, M. J. (2006). Technological pedagogical content knowledge: A framework for teacher knowledge. Teachers College Record, 108, 1017-1054.

Nicholson, M., \& Sanber, S. (2007). Integrating ICT into pre-service teacher education programs: Challenge and response. In M. Kompf (Ed.), Proceedings of the ISATT Conference (pp. 1-13). Ontario, Canada: ISATT.

Omaswa, F. G. (2014). Task force on job evaluation, re-organization of the staff structure and funding of Makerere University. Final report dated February 04, 2014, submitted to the Government of the Republic of Uganda.

Pierce, R., \& Ball, L. (2009). Perceptions that may affect teachers' intention to use technology in secondary mathematics classes. Educational Studies in Mathematics, 71, 299-317.

Puentedura, R. R. (2010). A brief introduction to TPCK and SAMR. Retrieved from: http://www.hippasus.com/rrpweblog/ archives/2011/12/08/BriefIntroTPCKSAMR.pdf.

Rogers, E. M. (2003). Diffusion of innovations. New York, US: Free Press.

Schmidt, D. A., Baran, E., Thompson, A. D., Mishra, P., Koehler, M. J., \& Shin, T. S. (2009). Technological pedagogical content knowledge (TPACK): The development and validation of an assessment instrument for pre-service teachers. Journal of Research on Technology in Education, 42, 123-150.

Shulman, L. S. (1986). Those who understand: Knowledge growth in teaching. Educational Researcher, 15 (2), 4-14.

Smarkola, C. (2007). Technology acceptance predictors among student teachers and experienced classroom teachers. Journal of Educational Computing Research, 37(1), 65-82.

Steketee, C. (2005). Integrating ICT as an integral teaching and learning tool into pre-service teacher training courses. Issues in Educational Research, 15(10), 101-112.

Tavakol, M., \& Dennick, R. (2011). Making sense of Cronbach's alpha. International Journal of Medical Education, 2, 53-55. doi: $10.5116 /$ ijme. $4 \mathrm{dfb} .8 \mathrm{dfd}$.

Taylor, L. (2004). How student teachers develop their understanding of teaching using ICT. Journal of Education for Teaching, 30(1), 43-56.

Venkatesh, V., Morris, M. G., Davis, G. B., \& Davis, F. D. (2003). User acceptance of information technology: Toward a unified view. MIS Quarterly, 27(3), 425-478. 